\title{
IMPLEMENTANDO UMA FERRAMENTA PARA MONITORAR AS CHUVAS ATRAVÉS DA PERCEPÇÃO E DA PARTICIPAÇÃO DAS PESSOAS
}

\author{
Dacy Câmara Lobosco \\ Centro Federal de Educação Tecnológica Celso Suckow da Fonseca - CEFET- RJ. \\ https://orcid.org/0000-0002-2022-4816 \\ Paulo V. R. Carvalho \\ Instituto de Engenharia Nuclear. \\ https://orcid.org/0000-0002-9276-8193 \\ Data de submissão: 03/06/2020 \\ Data de aprovação: 09/10/2020
}

\section{RESUMO}

As secretarias de defesa civil municipais têm grandes dificuldades em prever os impactos das chuvas devido às limitações dos sistemas de monitoramento existentes e do crescente de comunidades vulneráveis. $\mathrm{O}$ artigo descreve a construção de um aplicativo celular com base na metodologia Design Science Research que busca transformar toda a população de Nova Friburgo em voluntários de Defesa Civil compartilhando informações sobre as chuvas da cidade. A ferramenta visa uma quebra de paradigma educacional da população, transformando-as em participantes ativos no processo de prevenção de desastres. Os resultados mostraram que os dados apresentados aos agentes de defesa civil por pessoas em comunidades são de grande importância para as ações de resposta a emergências.

Palavras-chave: Defesa Civil. Colaboração. Sensemaking. Participação Popular.

\section{IMPLEMENTING A TOOL TO MONITOR RAINFALL THROUGH PEOPLE'S PERCEPITION AND PARTICIPATION}

\section{ABSTRACT}

Municipal civil defense departments have great difficulties in predicting the impacts of rainfall due to the limitations of existing monitoring systems and the growing number of vulnerable communities. The article describes the construction of a cellular application based on the Design Science Research methodology that seeks to transform the entire population of Nova Friburgo into Civil Defense volunteers sharing information about the city's rains. The tool aims at breaking the educational paradigm of the population, turning them into active participants in the disaster prevention process. The results showed that the data presented to civil defense agents by people in communities is of great importance for emergency response actions.

Keywords: Civil Defense. Collaboration. Sensemaking. Popular Participation

IMPLEMENTANDO UNA HERRAMIENTA PARA MONITOREAR LA LLUVIA MEDIANTE LA PERCEPCIÓN Y LA PARTICIPACIÓN DE LAS PERSONAS

\section{RESUMEN}

Las secretarías municipales de defensa civil tienen grandes dificultades para predecir los impactos de las lluvias debido a las limitaciones de los sistemas de monitoreo existentes y 
de las crecientes comunidades vulnerables. El artículo describe la construcción de una aplicación móvil basada en la metodología Design Science Research que busca transformar toda la población de Nova Friburgo en voluntarios de Defensa Civil que compartan información sobre las Iluvias de la ciudad. La herramienta intenta romper el paradigma educativo de la población, transformándola en participantes activos en el proceso de prevención de desastres. Los resultados muestran que los datos presentados a los agentes de defensa civil por personas de las comunidades son de gran importancia para las acciones de respuesta a emergencias.

Palabras clave: Defensa Civil. Colaboración. Sensemaking. Participación popular.

\section{INTRODUÇÃO}

No contexto de sistemas sociotécnicos complexos, a noção de "entendimento" assume um escopo inteiramente novo, um escopo macrocognitivo (KLEIN et al., 2003). Atores em situações de emergência devem enfrentar e entender situações complexas, dinâmicas e em evoluções ricas em significado. Embora os atores passem um tempo considerável percebendo os estímulos de um evento extremo, os estímulos levam a um conjunto muito grande e complexo de informações, e o objetivo mais alto do ator não é perceber estímulos, mas dar sentido a esses estímulos (KLEIN et al., 2007).

Dar Significado (ou "sensemaking") a situação que está ocorrendo é mais do que apenas interpretação, mas sim o estudo de como as pessoas geram o que interpretam em um processo contínuo usado para ordenar a realidade, reduzir a ambiguidade e gerenciar o inesperado (WEICK, 1995). Dada a natureza incerta dos incidentes de emergência, 0 sensemaking é visto como uma atividade central (JENSEN, 2009). Além disso, Landgren (2005a) observa que em situações com ambiguidade ou eventos inesperados, os esforços de conscientização das pessoas são visíveis, o que significa que o domínio de emergência favorece o estudo do sensemaking.

Em um ambiente de resposta a emergências de chuva forte, um Sistema Cognitivo Conjunto (JCS) (HOLLNAGEL; WOODS, 2005) envolve agentes de emergência, instrumentos utilizados para monitorar as chuvas, a população afetada e as informações coletadas durante o evento. Nessa perspectiva, Klein (2006, p. 227) reconhece que é raro encontrar uma tarefa importante que é realizada apenas por um indivíduo sem nenhum tipo de compartilhamento de informações. Klein et al. (2006b) descrevem o sensemaking como uma atividade social que permite o desenvolvimento de um contexto comum, indicando que o compartilhamento do sensemaking entre os vários elementos desse JCS seria fundamental para o bom funcionamento desse sistema em uma situação de emergência.

Para compartilhar o sensemaking neste JCS, é importante identificar pelo menos que tipo de informação é necessária, quem tem essas informações, que tipo de sistemas de informação serão usados e como essas informações serão compartilhadas entre os elementos do JCS. Esta pesquisa procura responder a todas essas perguntas e propõe uma solução que permitirá o JCS na prática.

Embora o uso de aplicativos móveis em situações de emergência já tenha um alto número de trabalhos, ainda existem lacunas que oferecem importantes oportunidades de pesquisa. Em nosso trabalho, nos concentramos no uso de um aplicativo para 0 compartilhamento de sensemaking entre a equipe de emergência e a população e como o uso de uma ferramenta colaborativa pode viabilizar um Sistema Cognitivo Conjunto (JCS). O grande desafio da implementação deste JCS seria uma mudança de cultura em que a população da cidade possa se transformar em um elemento importante e ativo dentro do trabalho de prevenção de desastres. 
Esta pesquisa é um estudo de caso em situações reais com voluntários interagindo com a equipe de emergência durante a ocorrência de chuvas e / ou durante a previsão de sua ocorrência. O objetivo é examinar a interação dentro do JCS e o fluxo de informações entre as entidades do JCS e avaliar os impactos dessa interação na percepção da população e da equipe de emergência durante situações de chuva forte. Buscamos identificar as principais dificuldades para a implementação de dispositivos móveis para compartilhar o sensemaking e os desafios para seu uso efetivo. A metodologia baseada no Design Science Research (DSR) evolui em ciclos iterativos através das seguintes etapas: revisão do trabalho relacionado; especificação de problemas; análise de soluções já desenvolvidas e lacunas existentes; entrevista com profissionais e pesquisadores da área de emergência; definição de uma solução e sua avaliação qualitativa.

\subsection{Contexto da Pesquisa}

Esta pesquisa foi inspirada na maior catástrofe ocorrida na região serrana de Nova Friburgo em 2011. Portanto, este evento é descrito nesta seção.

Na região serrana do Rio de Janeiro, durante o verão, há um fenômeno climático recorrente que é a Zona de Convergência do Atlântico Sul. A Zona de Convergência do Atlântico Sul, ZCAS na forma geralmente referida, é o principal sistema meteorológico de verão no Brasil responsável por um período prolongado de chuvas frequentes e volumosas em parte das regiões Norte, Centro-Oeste e Sudeste.

Em muitas áreas do Sudeste e Centro-Oeste, o alto volume de chuvas produzido durante a ZCAS, que opera em média por um período de 4 a 10 dias, pode representar uma grande parte das chuvas do trimestre chuvoso do ano. Quando o ZCAS se forma, uma extensa gama de nuvens carregadas persiste sobre o Brasil por vários dias consecutivos, atravessando o país da Amazônia ao Rio de Janeiro.

Outro fenômeno climático recorrente, mas ocorrendo o ano todo, são as frentes frias. $\mathrm{Na}$ América do Sul, as áreas contrastantes que formam as frentes frias coincidem com as regiões sul do Brasil e noroeste da Argentina. As frentes frias atingem as regiões sul e sudeste do Brasil o ano todo, cerca de três a cinco vezes por mês. As frentes frias estão associadas ao aumento de nuvens, precipitação, variações de vento e fortes mudanças de temperatura.

Por outro lado, a região serrana do Rio de Janeiro tem uma grande população e especialmente na cidade de Nova Friburgo não é diferente. Na cidade, em cerca de 50 anos, a população praticamente triplicou em um espaço territorial delimitado por cadeias de montanhas e rios (GASPARINI, 2012). Para acomodar essa população houve com o tempo desmatamento e ocupação das encostas que circundam a cidade. Essas ações desordenadas levaram a região a ser considerada como uma área de risco, com algumas áreas sujeitas a deslizamentos de terra e outras sujeitas a inundações (AGENDA 21 NOVA FRIBURGO, 2011).

Em 11 de janeiro de 2011, a região serrana do Rio de Janeiro foi atingida por uma tempestade que trouxe consequências para a região. A tempestade foi causada pela entrada de massas de ar provenientes da Zona de Convergência do Atlântico Sul (ZCAS) associadas a frentes frias procedentes do sul, fato considerado um evento natural de verão, esse fenômeno pode ser observado na figura 1. 
Figura 1 - Convergência do Atlântico Sul associado a frentes fria vindo do sul

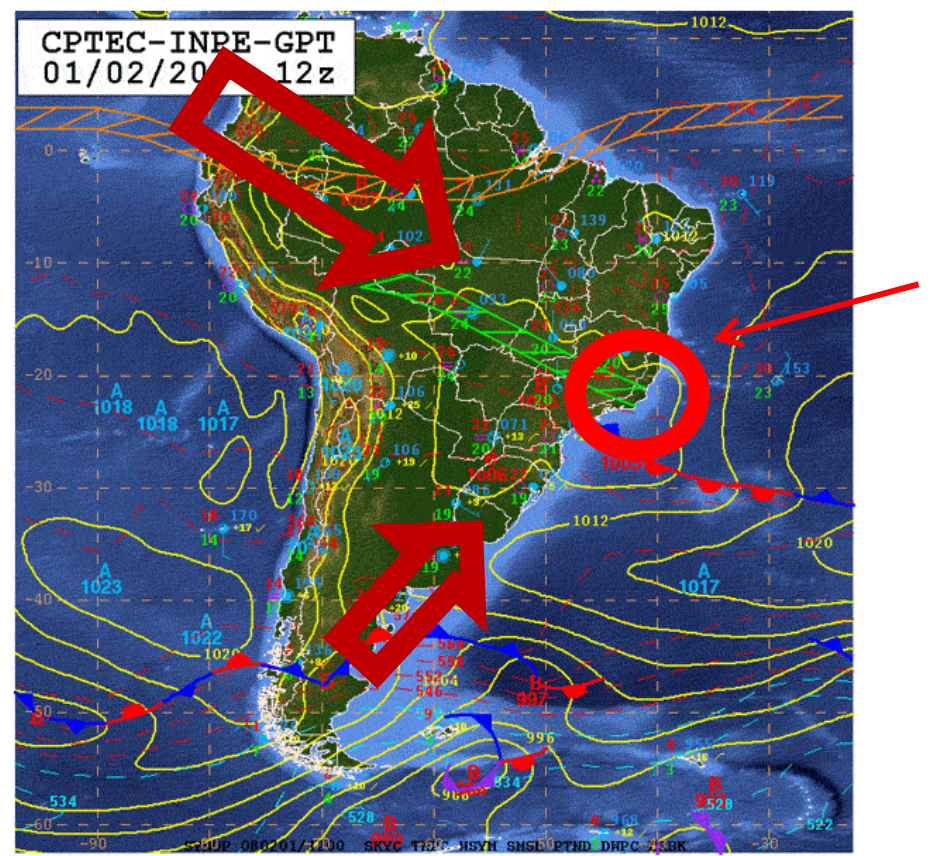

Fonte: CPTEC - 01/02/2012.

A grande quantidade de chuvas associada ao crescimento populacional e ao uso e ocupação incorretos do solo, com edifícios em locais de risco e mal estruturados, somados ao grande acúmulo de chuvas e erosões agiram de maneira que juntos culminaram em grandes deslizamentos de massa e inundações nessa região, com 864 mortes e 22.479 desabrigados. Entre todas as cidades atingidas pelo desastre, Nova Friburgo foi a que apresentou o maior número de mortes e uma maior extensão territorial alcançada pelo desastre. (BANCO MUNDIAL, 2012). Na Figura 2 é possível observar o centro de Nova Friburgo e os deslizamentos de terra que ocorreram em janeiro de 2011.

Figura 2 - Foto área do centro de Nova Friburgo Jan/2011 e suas cicatrizes

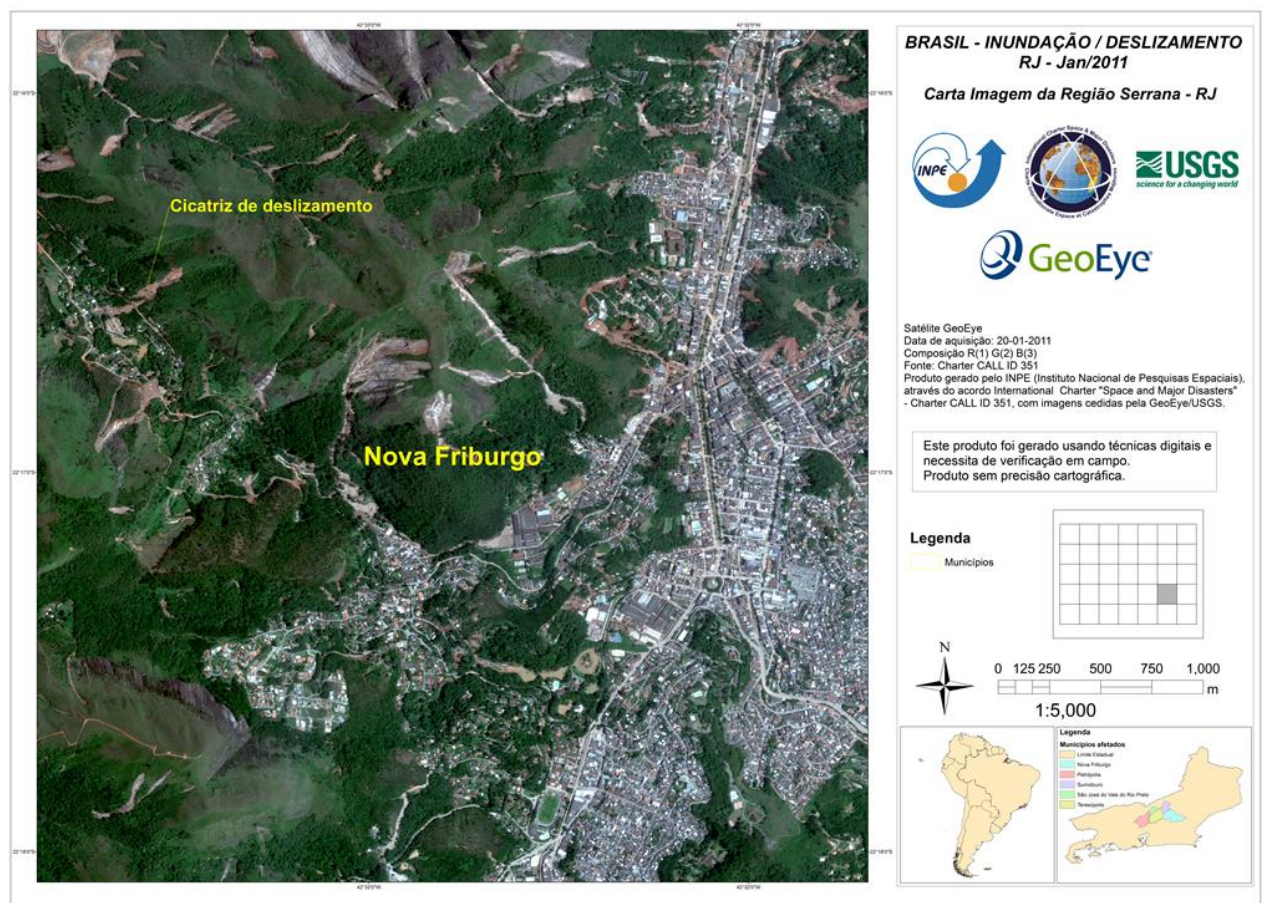

Fonte: INPE - 13/01/2011. 
Na foto da Figura 2 e nos relatórios da comunidade, a tempestade e os movimentos de massas ocorreram de maneira diferente em cada localidade de Nova Friburgo. Diante desse cenário, observa-se que a cognição da população em relação à chuva também foi modificada e contextualizada de acordo com a experiência de cada localidade da cidade. Isso significa que uma chuva de $50 \mathrm{~mm}$ para a percepção de uma determinada localidade corresponde a uma chuva de forte intensidade e para outra localidade na mesma cidade significa uma chuva de fraca intensidade.

\section{REFERENCIAL TEÓRICO}

Nas próximas subseções apresentamos uma revisão de literatura usando documentação acadêmica e do governo brasileiro sobre Defesa Civil, monitoramento de chuva, sensemaking e educação em emergência, os tópicos que enquadram essa pesquisa.

\subsection{Defesa Civil no Brasil}

As instituições de resposta a emergências geralmente são baseadas em princípios militares. Isto é devido ao tempo e a forma de sua criação. O primeiro responsável pelo combate a incêndios no Brasil, por exemplo, apareceu durante o Império de Pedro II e pertencia ao Arsenal da Marinha. Em 1880, já com uma Brigada de Incêndio formada, foi promulgado o decreto que concedia condição militar aos oficiais do Corpo (CBMERJ, 2017).

A Defesa Civil também tem laços estreitos com a estrutura militar do Corpo de Bombeiros. As primeiras organizações desse tipo foram criadas nos países envolvidos com a Segunda Guerra Mundial. O Serviço de Defesa Civil foi criado em 1942 como serviço de defesa antiaérea passiva. (SECRETARIA NACIONAL DE DEFESA CIVIL, 2017).

No Brasil, a Defesa Civil em sua origem era a estrutura responsável por estabelecer as necessidades básicas da comunidade em tempos de guerra. No entanto, com o tempo, diante de situações desastrosas, o poder público e a comunidade entenderam que as atividades de defesa civil eram essenciais não apenas em tempos de guerra, pois havia a necessidade de estruturar as comunidades para responder a vários tipos de desastres (NETO, 2007).

No início, as atividades de defesa civil visavam apenas minimizar as consequências de desastres, como as atividades de socorro pós-desastre (NETO, 2007). Atualmente, no entanto, além dessas atividades, também incluem trabalho preventivo para reduzir as consequências decorrentes desses eventos.

Portanto, princípios como hierarquia e cadeia de comando, ordem e disciplina, centralização e poder são encontrados nas estruturas dessas organizações. Esses princípios são alguns dos princípios fundamentais que formam a base da estrutura de Comando e Controle (C2).

De acordo com Grant (2017), os comandantes dessas organizações são invariavelmente apoiados pelo sistema C2, definido como instalações, equipamentos, comunicações, procedimentos e pessoal essencial para o comandante planejar, organizar, dirigir e controlar as operações dos recursos designados para realizar a missão. O pessoal da missão refere-se às pessoas que auxiliam o comandante na coleta de informações, no aconselhamento (geralmente especializado) e na implementação ou disseminação de decisões. O comandante e os assistentes serão chamados de equipe de comando.

De acordo com o CEPED / UFSC, 2012, as funções de defesa civil foram atualizadas pela Estratégia Internacional para Redução de Desastres e também mudaram no Brasil 
desde a publicação da Política Nacional de Proteção e Defesa Civil (PNPDEC). A Defesa Civil pode ser conceituada como um conjunto de ações preventivas, de mitigação, preparação, resposta e recuperação, destinadas a reduzir os riscos de desastres, com o objetivo de preservar a população, restaurar a normalidade social e a proteção civil. Percebemos nessa conceituação que a ação de defesa civil tem como objetivo principal a redução de riscos e desastres, que inclui cinco ações distintas e inter-relacionadas, que são ações de: prevenção; mitigação; preparação; resposta; e recuperação. Essas ações ocorrem de maneira multissetorial e nos três níveis de governo (federal, estadual e municipal), exigindo ampla participação da comunidade.

\subsection{Monitoramento da Chuva no Brasil}

No Brasil, o Governo Federal buscou consolidar um programa que permitisse ações coordenadas entre os órgãos envolvidos em questões relacionadas ao monitoramento e gerenciamento de alertas, alarmes e articulações, respostas e mobilizações. Em julho de 2011, um decreto presidencial criou o Centro Nacional de Monitoramento e Alerta de Desastres Naturais (CEMADEN), uma agência vinculada ao Ministério da Ciência, Tecnologia, Inovação e Comunicações (MCTIC). O principal objetivo do CEMADEN é monitorar o clima e emitir alertas para reduzir a vulnerabilidade social, ambiental e econômica resultante desses eventos. (CEMADEN, 2018)

O CEMADEN foi criado em parceria com várias instituições para implementar, complementar e consolidar a rede de instrumentos meteorológicos, hidrológicos e geotécnicos de monitoramento ambiental. Essa rede inclui dados de pluviômetros automáticos, dados obtidos por radares meteorológicos, plataformas para monitorar a umidade do solo e pluviômetros semiautomáticos distribuídos em comunidades em áreas de risco. (CEMADEN, 2018).

De acordo com a Secretaria Nacional de Defesa Civil (2012), o CEMADEN é o órgão federal responsável pelo envio de dados de chuva e radar ao CENAD, e o CENAD é responsável pelo envio de dados, alertas e ações de coordenação das diversas defesas civis instaladas nos municípios afetados pela previsão. Por fim, as equipes de Defesa Civil de cada cidade devem ter competência para tomar as decisões de emergência necessárias em relação à população residente no município afetado pela previsão.

Durante observações de campo na defesa civil de Nova Friburgo, analisamos os principais instrumentos meteorológicos utilizados pelos agentes para a previsão de chuva. Esses instrumentos são sites disponibilizados pelo CEMADEN ou por institutos governamentais parceiros em previsões meteorológicas. Os instrumentos mostram imagens de satélite com dados da chuva que ocorreu e uma previsão de chuva futura, como mostrado nas figuras 3 e 4 . Com base nesses dados e nos avisos emitidos pelo CEMADEN é que a equipe de defesa civil toma decisões de emergência que impactarão a vida da população da cidade.

Um aspecto interessante a ser observado é a qualidade das informações fornecidas pelo CEMADEN nas previsões e alertas. Em relação à qualidade das previsões e avisos, 0 CEMADEN (2017) nos diz que enfrenta limitações em relação às incertezas das previsões meteorológicas; problemas no diagnóstico da natureza dos fenômenos que operam em uma determinada área, principalmente em termos de duração e tamanho, dificuldades para obter informações ininterruptas de precipitação pluviométrica, áreas com baixa densidade de pluviômetros que não fornecem dados do passado para cobrir uma área geográfica significativa, falhas e atrasos no recebimento de dados de chuva pela rede hidrológica, rede hidrológica ruim, imprecisão na descoberta dos parâmetros de precipitação em cada localidade de cada cidade para prever deslizamentos em massa, falha na obtenção de informações sobre movimentação de terra, condições das ruas, lixões, ralos entupidos, 
vazamentos de líquidos, condições de construção residencial, falhas na descoberta de chuvas que ocorrem em municípios vizinhos que afetam o município observado.

Figura 3 - Dados do Passado

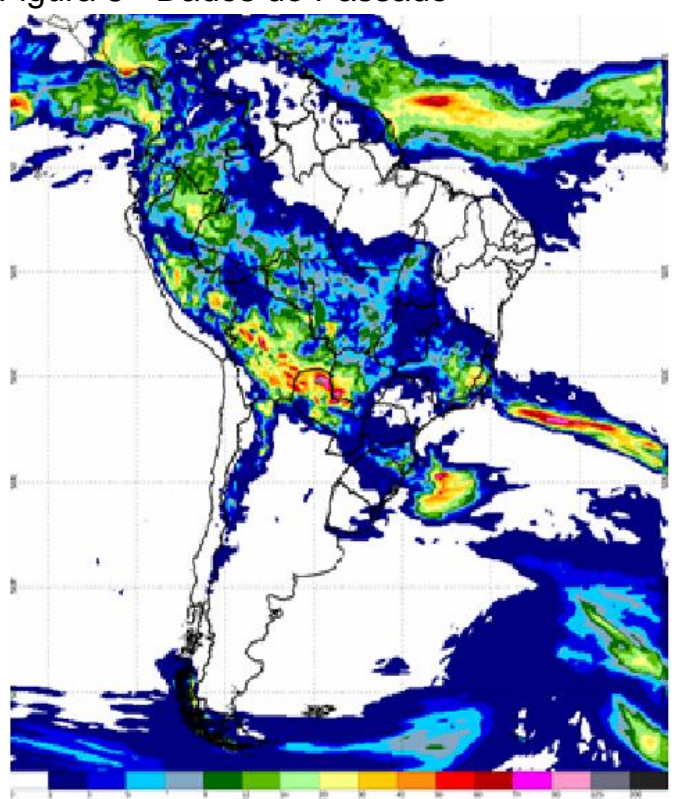

Fonte: INMET - 26/10/2016.

Figura 4 - Dados do Futuro (alerta)

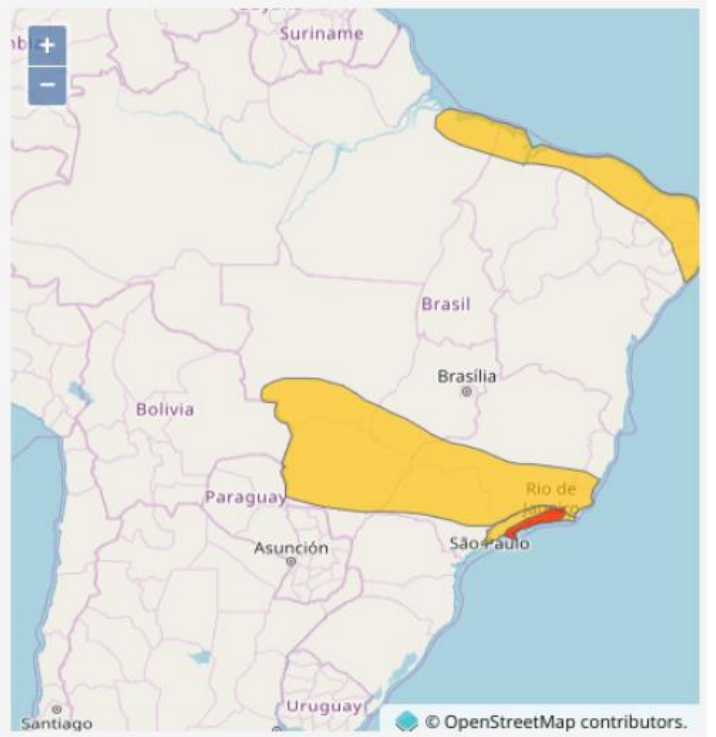

Fonte: CPTEC/INPE - 26/10/2016.

Todos esses fatores indicaram que os agentes de defesa civil têm vários problemas em descobrir o que realmente ocorre no campo em tempo real e entender as situações de emergência.

Dolif et al. (2013) já observaram essas questões investigando os desafios dos agentes do ALERTA RIO na análise dos dados meteorológicos fornecidos pelo CEMADEN e outros institutos meteorológicos. O estudo de campo mostrou questões sobre integração de dados, desempenho de modelos meteorológicos e também o pedido de um agente de que queria uma "janela para o exterior" para facilitar o seu trabalho de observação meteorológica. Eles explicam que olhando para o exterior, eles poderiam em tempo real validar dos dados computacionais (gráficos e previsões).

Tais problemas nos dados meteorológicos e suas análises, confirmados pelo CEMADEN e ratificados por observações de campo, indicaram que a tomada de decisão das equipes de defesa civil com base apenas nesses dados poderia ser melhorada com 
informações mais detalhadas sobre o que está acontecendo em campo, informações provenientes das comunidades locais em situações de chuva forte.

Além disso, analisando os relatórios da comunidade após fortes chuvas, pode-se observar que há avisos frequentes de chuvas fortes que não acontecem (falso-positivo) ou situações em que a comunidade não é avisada e chuvas fortes ocorrem (falso-negativo). Esses alertas inadequados ou falsos (positivos ou negativos) podem ser entendidos devido aos problemas nos dados e infraestrutura meteorológicos e às incertezas naturais nessas medições. Uma nova estrutura C2 de comando e controle que inclua formalmente os conselhos, avisos e percepções da população local, juntamente com maneiras de capturar, organizar e estruturar essas informações facilitaria a criação de sensemaking e a decisão das equipes de resposta a emergências.

Esta pesquisa procura preencher essa lacuna, encontrando soluções tecnológicas sem grandes investimentos financeiros em infraestrutura e de maneira colaborativa e criativa para incluir todos os atores desse Sistema Cognitivo Conjunto para participar de soluções de prevenção e resposta a emergências. A solução proposta visa, por um lado, disponibilizar informações de defesa civil de forma mais personalizada para cada localidade da cidade e, por outro lado, permitir que as equipes de defesa civil obtenham dados da população em tempo real favorecendo os agentes e o sensemaking para tomada de decisão.

\subsection{Participação popular, educação em emergência}

Segundo Lima, Gomes e Aguiar (2019), os riscos advindos da evolução da modernidade e da industrialização estão cada vez mais presentes na vida das pessoas, e para a mitigação desses riscos há a necessidade de se criar ferramentas e o uso de tecnologias para tornar a gestão desses riscos de forma mais participativa e para que a população contribua na geração de dados para auxiliar no monitoramento dos riscos da cidade. Para que a gestão compartilhada funcione o engajamento das partes do JCS requer empenho e compromisso de toda a sociedade civil em colaborar e compartilhar conhecimento.

De acordo com Lima, Gomes e Aguiar (2019), a utilização de tecnologias torna a população participativa e ativa na mitigação dos riscos tornado a gestão urbana mais participativa. Por conta do aumento da participação muitas perspectivas e interpretações conflitantes surgem e Burnett, Wooding e Prekop (2004) fornecem uma solução tomando o conceito de comunidade de prática que é centrada em um domínio bem definido de conhecimento e experiência, onde os membros da comunidade compartilham um conjunto comum de padrões de interpretação, suposições implícitas e crenças. O objetivo da comunidade é criar, manter e compartilhar seus conhecimentos dentro de um domínio bem definido. Com isso a comunidade de prática produz uma profundidade de conhecimento que se relaciona com a formação de novos padrões de percepções, novas formas de entender o mundo, a ruptura das crenças existentes e, finalmente, a inovação em todo o processo de gestão de emergência.

\subsection{Compartilhando Sensemaking em resposta a emergências}

Criar significado para o que está acontecendo em resposta a emergências é muito difícil. Os eventos de emergência podem ter baixa previsibilidade porque as informações são imprecisas (por exemplo, as ferramentas meteorológicas têm áreas de sombra) e porque as demandas e os recursos disponíveis mudam constantemente, caracterizando um ambiente complexo. 
Para lidar com ambientes complexos que envolvem pessoas e tecnologia, Hollnagel e Woods (2005) desenvolveram a estrutura do Joint Cognitive System (JCS) como uma maneira de executar gerenciamento e controle sobre a incerteza, atingindo um conjunto razoável de condições de desempenho (HOLLNAGEL; WOODS, 2005). Nesse tipo de sistema, é necessário abordar os fatores humanos (individuais e / ou coletivos) e as várias possibilidades de mudança de estado do sistema, garantindo que a função de artefatos sociais e tecnológicos seja designada para poder compartilhar o sensemaking dos eventos observados (por exemplo: chuvas fortes) em tempo suficiente para tomar ações preventivas e se comunicar entre as partes do JCS.

Landgren $(2004 ; 2005 b)$ descreveu o processo de iluminação progressiva de uma situação, e é mais evidente no contexto de emergência, porque os dados sobre o evento observado são analisados à medida que os eventos evoluem, gerando novos dados que envolvem um processo iterativo de interpretação comprometida, na qual o comportamento (ações) de um indivíduo influencia o próprio e os outros com seus sentimentos e percepções sensoriais. A ação comprometida cria o contexto para interpretação, e esse contexto (dados e interpretações) é compartilhado entre as outras partes do JCS. Ao fazer isso, reduz o foco dos atores a um subconjunto de pistas de informações disponíveis, o que sugere uma justificativa razoável das ações das partes envolvidas (Landgren, 2004). Dessa forma, sensemaking em resposta a emergência é mais do que apenas o estudo das interpretações de uma situação, mas o estudo de como as pessoas geram, se comunicam e compartilham o que interpretam e a influência dessas interpretações nas ações de outras partes do JCS (WEICK, 1995).

Para Para Weick, Sutcliffe e Obstfeld (2005), o compartilhamento de sensemaking entre as partes do JCS envolve tornar explícito, público, relevante, ordenado e claro o que é tácito, privado, complexo, casual e histórico. Isso é alcançado através do diálogo interativo, baseado na linguagem e na conversação para formular e trocar experiências e representações simbolicamente codificadas (WEICK; SUTCLIFFE; OBSTFELD, 2005, p. 413).

Vale ressaltar que, no âmbito das situações de fortes chuvas na cidade em que o estudo de caso foi realizado, observou-se que em diferentes localidades a experiência e as representações simbólicas sobre a intensidade da "mesma" chuva são diferentes. E compartilhar essas interpretações requer uma linguagem compartilhada ou algum artefato tecnológico que a torne viável (JOHANNESEN, 2008). A comunicação de interpretações individuais em situações de emergência permite que as partes do JCS gerem avaliações conjuntas, resolvam problemas de forma colaborativa e rapidamente detectem e se recuperem de ações inadequadas anteriormente tomadas (JOHANNESEN, 2008). No contexto de emergência sob fortes chuvas, o compartilhamento de sensações significa vincular as soluções e ações a todos os atores envolvidos na situação.

Para transformar as percepções das pessoas em informações explícitas e públicas em respostas de emergência, Kirsh (2013) mostra o benefício de usar artefatos tecnológicos como representações externas para melhorar as funções cognitivas, afirmando que elas: (a) fornecem uma estrutura que pode servir como um objeto compartilhado de pensamento; (b) Cria referências persistentes e estáveis; (c) Facilitar as representações e redesenhos dessas representações; (d) São frequentemente uma representação mais natural da estrutura do que as representações mentais; (e) Facilitar o cálculo de codificação de informação mais explícita; (f) Permitir a construção de estruturas arbitrariamente complexas; (g) Reduza o custo do controle do pensamento - eles ajudam a coordenar o pensamento. Juntas, essas funções permitem que as pessoas pensem mais poderosamente com representações externas do que sem elas. (KIRSH, 2013, p. 171). 
Tanto Pirolli e Card (2005) como Attfield e Blandford (2011) consideram a transformação de representações externas como um componente-chave do processo de sensemaking. Pirolli e Card (2005) descrevem como os agentes usam artefatos como mapas, bancos de dados e redes para organizar e entender informações sobre pessoas, organizações, tarefas, clima, chuva, para desenvolver e comunicar ideias. Nesta pesquisa, o sensemaking pode ser visto como um processo de transformação de representações internas e mentais em externas, como quadros e artefatos que representam informações, a partir de seu estado bruto, de uma forma que incorpora uma interpretação ou uma tomada de decisão, e depois formulados e adequados para comunicação dos envolvidos (Pirolli e Russell, 2011).

Para Faisal, Attfield e Blandford (2009), essas representações externas formam quadros ou esquemas que orientam e influenciam as interações com os dados, indo além da visão de que o sensemaking ocorre apenas na mente das pessoas, para um contexto em que o sensemaking é uma atividade tecnologicamente mediada (ATTFIELD; BLANDFORD, 2011). Consequentemente, o sensemaking pode ser visto como parcialmente definido pelas ferramentas e artefatos disponíveis.

\subsection{Sensemaking e aplicativos móveis}

Tan et al. (2017) afirma que dois grandes movimentos de comunicação deram origem à computação em crise: a mudança de uma abordagem Top-Down para uma interação de Botton-Up e o crescente uso de mídias sociais e aplicativos móveis, porque por meio dessas tecnologias móveis os usuários têm acesso incomparável às informações. Aplicativos móveis projetados especificamente para desastres geralmente têm uma variedade de recursos, geralmente existem cinco propósitos: (1) crowdsourcing, (2) colaboração, (3) disseminação de alertas e informações, (4) agrupamento de informações e (5) notificação gerada pelo usuário durante desastres. Os três primeiros propósitos são enriquecer a conscientização da situação, coletando informações com o envolvimento do público; enquanto os dois últimos se concentram na entrega resiliente de informações críticas entre as autoridades e o público. Como exemplo de aplicativos de crowdsourcing, podemos mencionar o TweetClicker e o ImageClicker, usado para avaliar a situação do tufão nas Filipinas, solicitando aos voluntários que rotulem a relevância dos tweets e imagens do desastre (POBLET; GARCÍA-CUESTA; CASANOVAS, 2014b )

Ley et al. (2014) desenvolveram o aplicativo móvel colaborativo chamado MobileMap, projetado para ajudar os bombeiros a chegarem mais rapidamente ao cenário de emergência, trocar informações digitais durante a resposta de emergência e reduzir a necessidade de comunicação por rádio. As ferramentas geo-colaborativas baseadas na Web também foram examinadas: Chang e Li (2007) integram ferramentas colaborativas, como bate-papo e vídeo, para apoiar a conscientização e colaboração dos participantes. Muitos deles baseados na Web são descritos por Liu e Palen (2010), que se concentram particularmente na fusão da cultura profissional de SIG com a cultura neo-geográfica participativa para enfrentar os desafios de mapeamento.

Ávila (2018) afirma que, nos últimos anos, foram feitos vários esforços para incorporar ciência e tecnologia nas diferentes fases do gerenciamento de emergências e na fase pré-emergencial. Exemplos de tecnologias e ferramentas que dão suporte à fase de pré-emergência incluem o sistema global de conscientização sobre inundações GloFAS, que é baseado em uma simulação hidrológica distribuída de previsões do tempo, o aplicativo Sai Fah (The Flood Fighter) desenvolvido pela UNESCO-Bangkok para dispositivos móveis aumentam a conscientização sobre questões de segurança contra inundações, criada após a enchente de 2011 na Tailândia, a ferramenta Profiler projetada para aumentar a conscientização e a compreensão das organizações que se preparam 
para uma emergência, o aplicativo Tanah3, desenvolvido para fornecer lições de sobrevivência em caso de tsunami ou terremoto em todas as fases de um desastre (preparação, resposta e recuperação), o jogo de simulação Stop Disasters4, que permite ao usuário treinar em vários cenários, como tsunamis, furacões, incêndios florestais, inundações e terremotos (GAMPELL; GAILLARD, 2016), o simulador ETC que tem a capacidade de simular o gerenciamento de desastres por meio do ADMS (Advanced Disaster Management Simulator 5) e o estrutura do SAGA, que integra um conjunto de ferramentas para o gerenciamento de planos de emergência que suportam as diferentes etapas do ciclo de vida do plano de emergência.

\section{METODOLOGIA}

Esta pesquisa segue o processo iterativo da Design Science Research (DSR), desde a descoberta de fatos até a conscientização sobre os problemas, planejamento de soluções / ações, design de artefatos, avaliação e reflexão sobre os problemas. A Design Science Research tem sido amplamente utilizada nas áreas de engenharia e sistemas de informação, visando o desenvolvimento e soluções de projeto para resolver classes de problemas, propor novos artefatos e propor melhorias ou alternativas às soluções existentes (AKEN 2004; HEVNER et al., 2004).

Segundo Aken (2004), a principal missão da Design Science é desenvolver conhecimento para o design e desenvolvimento de artefatos. Hevner et al. (2004) afirmam que ele procura preencher a lacuna entre teoria e prática e estimular o rigor necessário para garantir a confiabilidade nos resultados alcançados.

O método é dividido em etapas altamente interconectadas e algumas vezes sobrepostas, de uma maneira que os resultados de alguma etapa influenciam na revisão de uma anterior. A fase de descoberta de fatos inclui revisão da literatura e estudos etnográficos de campo em uma pesquisa fundamentada que visa o desenvolvimento de artefatos aplicados e úteis. Os estudos de campo possibilitam o envolvimento de agentes da defesa civil e as pesquisas em uma construção social (CARVALHO et al., 2016) organizada conforme indicado na Figura 5.

Figura 5 - Construção Social

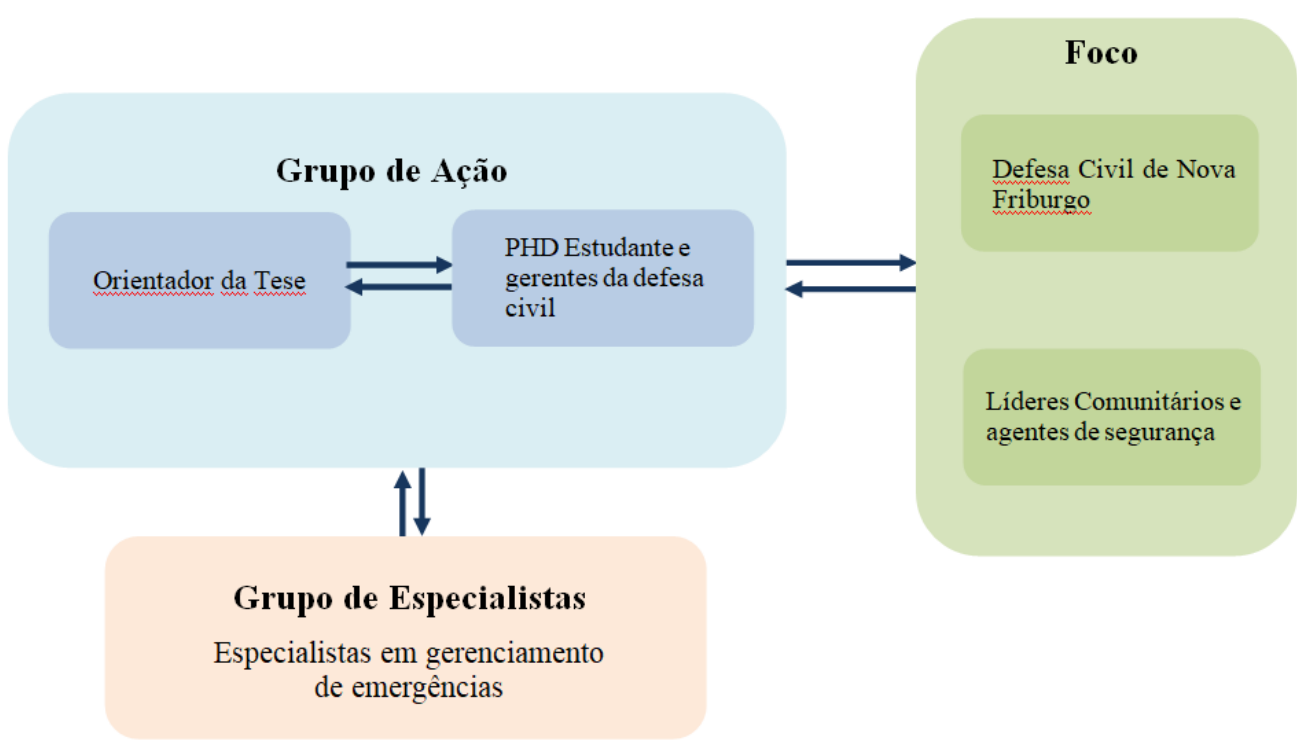

Fonte: Elaborado pelo autor (2019).

O Grupo de Ação foi composto por pessoas da universidade e da defesa civil interessadas em desenvolver a solução. Os grupos focais foram formados por pessoas que 
forneceram dados e informações e / ou participaram de outras etapas da pesquisa-ação, como uso e validações. O grupo de especialistas era composto por outros professores e pesquisas em ergonomia e pesquisa de gerenciamento de emergências.

A descoberta do fato envolveu as etapas abaixo:

- Revisão da literatura sobre organização de Defesa Civil no Brasil, participação popular em emergência, sensemaking sobre gerenciamento de emergências e aplicações móveis;

- Observação direta de agentes de defesa civil no centro de comando e controle em situações de chuva;

- Entrevistas semiestruturadas com agentes de defesa civil;

- Oficinas com agentes e autoridades da cidade;

- Compilação de dados, confronto participativo e análise.

- Com base nos resultados da etapa anterior, o desenvolvimento da solução / aplicativo envolveu:

- Definição de uma estrutura de sistema cognitivo conjunto a ser usada para o desenvolvimento de aplicativos em situações de chuva forte;

- Desenvolvimento de aplicativo móvel para compartilhamento de sensações entre pessoas e agentes da defesa civil;

- Avaliação e validação preliminar durante experimentos semi-controlados em situações reais de chuva. Por fim, o aplicativo foi entregue para ser utilizado por toda a população da cidade.

\subsection{Proposta de Solução}

Como já explicado, na cidade de Nova Friburgo, é difícil obter informações precisas no local, no instante que está ocorrendo e o possível impacto sobre fortes chuvas. Obter e entender o mais rápido possível informações mais precisas farão diferença na resposta a emergências. A solução proposta é baseada em três pontos: a) Informar à comunidade as percepções da Defesa Civil local com base em dados e informações provenientes de agências meteorológicas e nacionais de Defesa Civil; b) Informar a Defesa Civil local sobre a percepção da população vulnerável sobre a chuva que está ocorrendo; c) Construir um artefato para comunicação e interação entre a população e a defesa civil, a fim de melhorar o funcionamento do JCS, mesmo em um estágio inicial de uma situação de forte chuva.

No ciclo de gerenciamento de emergências (mitigação, prevenção, resposta e recuperação), o foco desta pesquisa está na fase de prevenção e resposta precoce. Um dos objetivos é integrar as percepções da população sobre o volume e o impacto das chuvas com vários outros dados climáticos, fornecendo uma visão contextualizada que beneficia a criação de sensemaking, incluindo novas informações do campo que podem apoiar a tomada de decisão. O modelo da estrutura conceitual básica é mostrado na Figura 6.

A ideia é focar no desenvolvimento em ciclos, para que novos recursos sejam desenvolvidos em novos ciclos e se integrem aos ciclos anteriores, de acordo com um grau de maturidade obtido pelo uso, prática e avaliação de resultados. Com base em entrevistas com pesquisadores, buscamos criar um artefato inicialmente flexível e adaptável que permita que outros aplicativos sejam conectados enviando e recebendo informações. $\mathrm{O}$ desenvolvimento pode começar simples e expandir o número de recursos para o uso de novas tecnologias à medida que a solução avança. A ideia de novos ciclos de desenvolvimento visa refinar e evoluir para tornar o funcionamento do JCS o mais natural possível, facilitando a criação de sensemaking entre as partes envolvidas. A estrutura permite o uso de novas tecnologias para compartilhar as percepções das pessoas sobre a 
chuva com outras aplicações de serviço público, como tráfego, cruzando informações importantes e ampliando o sensemaking dos cidadãos.

Figura 6 - Framework como um Joint Cognitive Systems

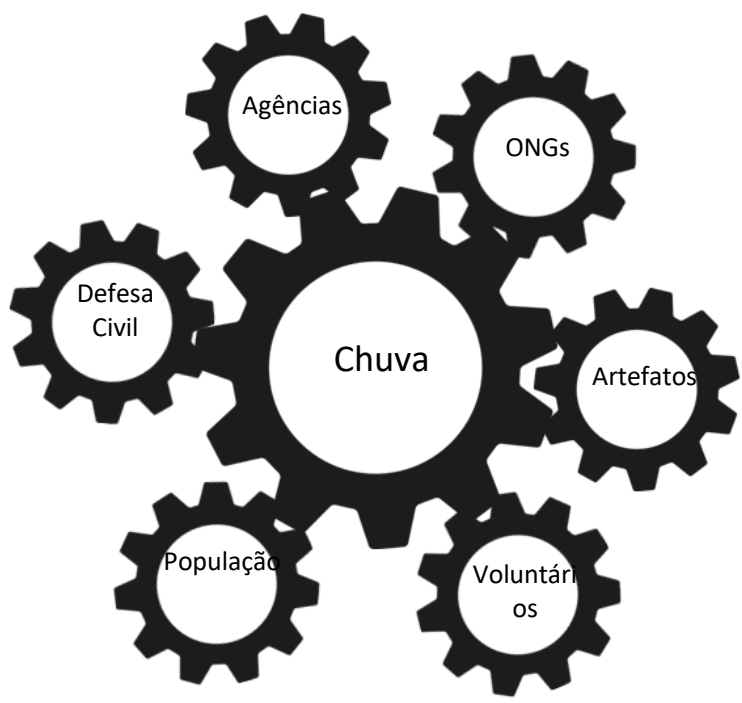

Fonte: Elaborado pelo autor (2019).

Um aplicativo foi desenvolvido de acordo com os conceitos de um sistema colaborativo baseado em smartphones para interação entre a população e os membros da equipe de defesa civil. Após o desenvolvimento, o sistema foi testado em situações reais de chuva. Os resultados obtidos foram comparados com as previsões dos órgãos oficiais, a fim de verificar a influência do compartilhamento de sensemaking durante a ocorrência das chuvas e se o mapeamento das percepções da população sobre o nível e o impacto das chuvas foi relevante para a tomada de decisão.

O objetivo é tornar toda a população de Nova Friburgo uma rede de sensores para proporcionar insights sobre as chuvas. Como já foi dito por Goodchild (2007), a questão é aproveitar a inteligência e a experiência de cada pessoa na área em que vivem, aproveitando o fato de que os humanos são sensores inteligentes capazes de fornecer dados relevantes para a emergência. Os dados da população são compartilhados com as equipes de emergência, por meio de um sistema colaborativo para fornecer informações entre os envolvidos sobre o real impacto das chuvas em cada localidade e sobre quais ações estão em andamento. As percepções da população preenchem um mapa da situação das chuvas, como quadros de dados disponibilizados para a população e a equipe de emergência ao mesmo tempo, de maneira que ambos são capazes de avaliar e criar sensemaking em relação ao impacto das chuvas.

Figura 7 - Compartilhando sensemaking

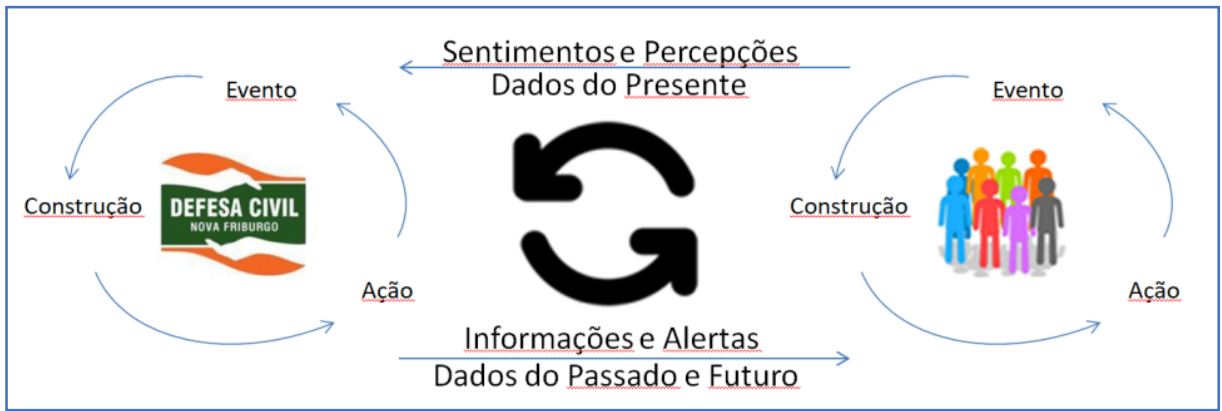

Fonte: Elaborado pelo autor (2019).

Existem dois eventos acionadores que ativam o fluxo da cognição e as atividades de sensemaking associadas a eles. Eventos Acionadores: 1) Informação sobre a chuva (Post 
Spontaneous) e 2) Publicação de Alertas e Informativos (Publish Post). O processo de coleta de informações apresentado na Figura 8 será detalhado abaixo, onde os principais grupos de usuários serão identificados, seus canais de comunicação através de fluxos de mensagens.

Figura 8 - Processo de colaboração em relação a chuva

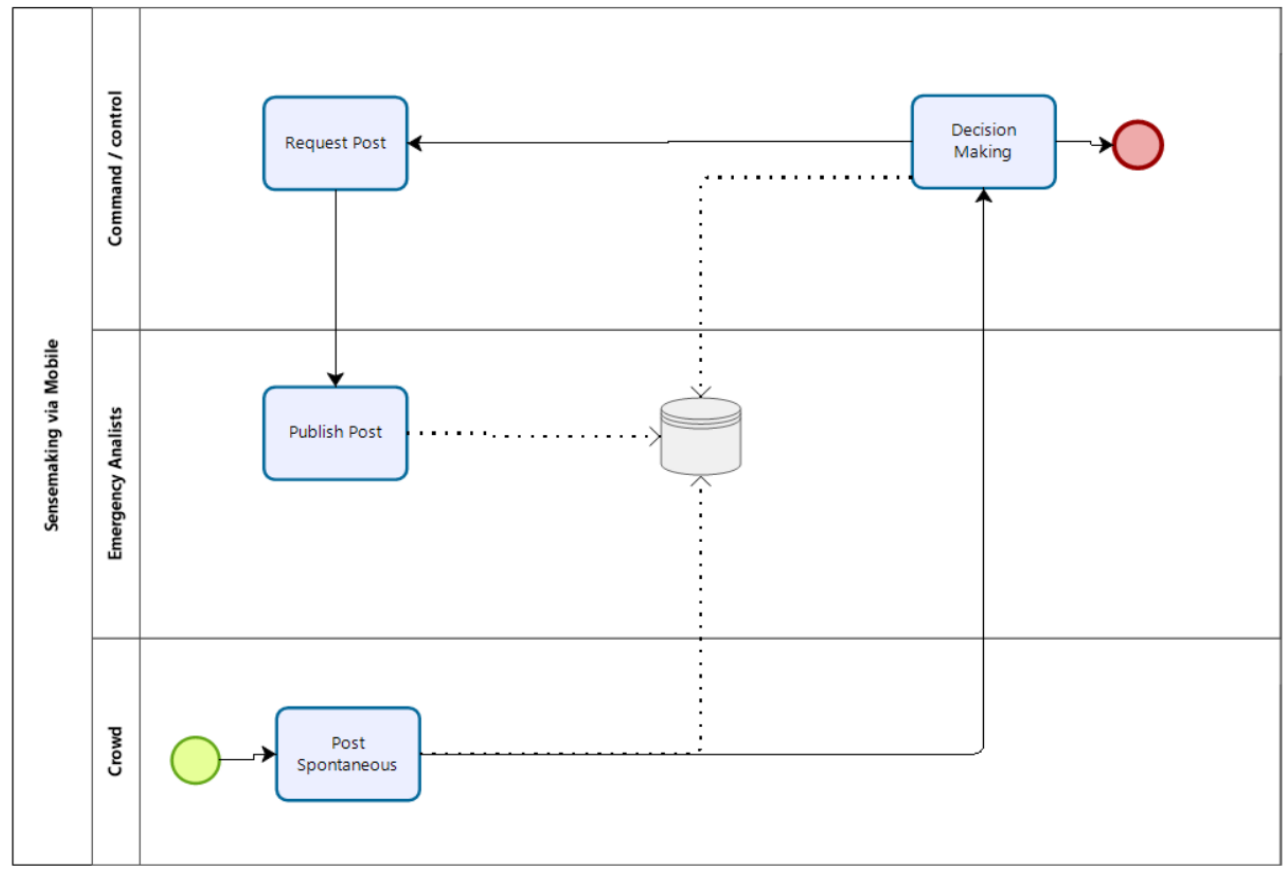

Fonte: Elaborado pelo autor (2019).

A) Informação sobre a chuva (Post Spontaneous): Principal forma de interação da população com a defesa civil. Através deste canal, a população pode informar sua percepção de chuva através de um aplicativo móvel. No post que vem da população, virá a posição do GPS, o número do celular e a percepção da chuva. Na figura 9 , mostramos a interface do telefone celular com a população, informando seu sentido nas chuvas. A intensidade da chuva está associada a uma cor, o que será importante para a plotagem de informações para defesa civil e para facilitar a análise cognitiva.

Figura 9 - Interface para população informar sua percepção da chuva

\begin{tabular}{|c|c|}
\hline \multicolumn{2}{|r|}{ Reportar Chuvas } \\
\hline \multicolumn{2}{|c|}{$\begin{array}{l}\text { - Por favor, selecione } \\
\text { a intensidade da chuva no momento. } \\
\text { - Fotografe o local de risco, } \\
\text { caso queira. } \\
\text { - Clique em enviar. }\end{array}$} \\
\hline \multicolumn{2}{|r|}{ Intensidade de chuva } \\
\hline 0 & Muito Forte \\
\hline 0 & Forte \\
\hline 0 & Moderada \\
\hline 0 & Fraca. \\
\hline \multicolumn{2}{|r|}{ Imagem do local } \\
\hline Toq & na imagem para alterar/adicionar \\
\hline
\end{tabular}

Fonte: Elaborado pelo autor (2019).

B) Publicação de Alertas e Informativos (Publish Post): Sempre que houver uma atualização disponível, os agentes deverão informar as partes interessadas. Tipos 
de atualizações: previsão de chuvas (dados futuros), níveis de alerta, situação das chuvas nas últimas horas (dados do passado), resposta a mensagens e dúvidas do público, informações, solicitação de evacuação para pontos de apoio, boletins de situação de emergência. A Figura 10 mostra a interface da população quando recebe uma informação ou alerta da defesa civil.

Figura 10: Informações da equipe de emergência para a população
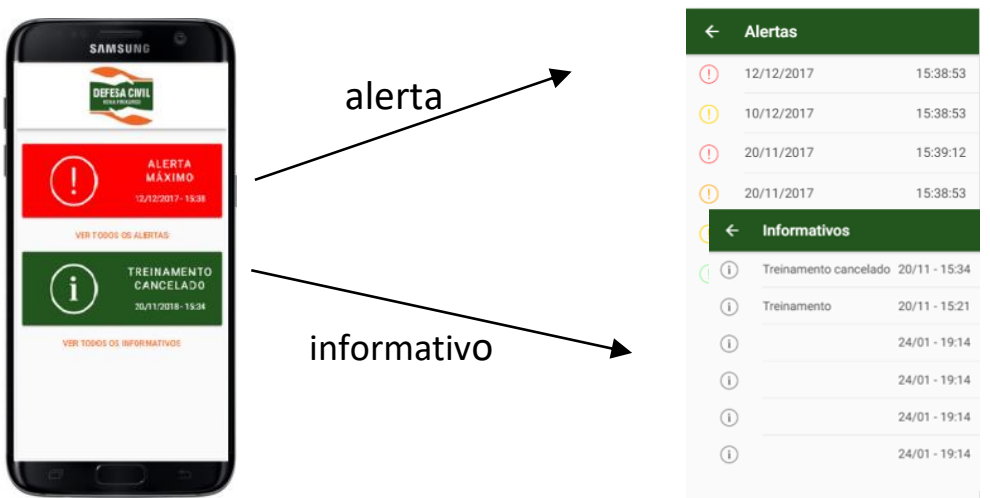

Fonte: Elaborado pelo autor (2019).

C) Solicitar postagem (Request Post) - O comando e controle solicita à equipe de analistas que utiliza a interface WEB o envio de informações, alertas, orientações, respostas às expectativas e dúvidas da população para o aplicativo celular.

D) Tomada de Decisão (Decision Making) - O comando e controle, com posse das informações recebidas pela população, toma decisões de ação: envia alertas, informativos, mensagens que visam gerenciar as expectativas da população, enviar veículos, combater as consequências de um evento em andamento, etc.

E) Data Lake - repositório centralizado que permite armazenar todos os dados estruturados e não estruturados provenientes de percepções da população.

\section{ANÁLISE E DISCUSSÃO DOS RESULTADOS}

Após o primeiro ciclo da DSR, a solução proposta foi avaliada em situações reais de chuva na cidade de Nova Friburgo. Agentes da defesa civil e voluntários das comunidades participaram dos testes. Durante as situações de chuva, o objetivo principal era comparar os dados provenientes dos voluntários e agentes com as previsões das agências governamentais, vendo como os primeiros realmente melhoram o senso geral sobre o nível da chuva. Esse teste foi realizado por 14 dias entre janeiro e fevereiro de 2019, período escolhido por ser um dos mais chuvosos do ano. Durante o período de testes, foram armazenadas informações das previsões oficiais das agências e a percepção da chuva de voluntários e agentes por meio da ferramenta. Vale ressaltar que os agentes e voluntários que testaram a ferramenta são pessoas que trabalham ou trabalharam há anos em situações de emergência, como coronel de bombeiros, chefe da defesa civil, pessoas que são referências em suas comunidades quando se trata de apoiar situações de emergência. A Figura 11 ilustra como é o mapa da ferramenta e como apresenta os dados para as pessoas sobre sua contribuição da chuva. A Figura 11 é uma captura de tela durante o evento de chuva em 31/01/2019. 
Figura 11 - Google Maps com a percepção da população sobre as chuvas

Dona Mariana

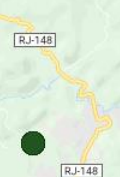

[492]

4492]

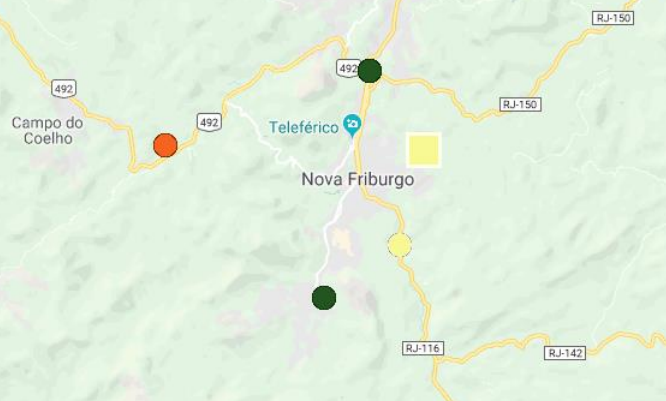

Bom Jardim

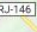

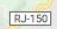

Fonte: Elaborado pelo autor (2019).

Uma contribuição importante que podemos destacar da captura de tela da Figura 11 em comparação com a previsão é que a previsão sempre fornece um cenário único do pior caso para toda a cidade, e a ferramenta durante os testes fornece dados com a intensidade da chuva de cada local da cidade. Para fins de comparação entre os dados de previsão e os dados do aplicativo, usamos o pior caso que ocorreu no dia dos dados do aplicativo. Durante os 14 dias de testes, o Quadro 1 compara as previsões das agências e a contribuição dos voluntários por meio do aplicativo:

Quadro 1 - Comparação entre a previsão e os dados do aplicativo

\begin{tabular}{|c|c|c|}
\hline Dia & Previsão & App (pior caso) \\
\hline $25 / 01 / 2019$ & Fraca & Muito Forte \\
\hline $28 / 01 / 2019$ & Sem chuva & Sem chuva \\
\hline 29/01/2019 & Sem chuva & Sem chuva \\
\hline $30 / 01 / 2019$ & Sem chuva & Sem chuva \\
\hline $31 / 01 / 2019$ & Sem chuva & Forte \\
\hline 01/02/2019 & Sem chuva & Sem chuva \\
\hline 04/02/2019 & Forte & Sem chuva \\
\hline 05/02/2019 & Low & Moderada \\
\hline 06/02/2019 & Low & Moderada \\
\hline 07/02/2019 & Forte & Moderada \\
\hline $11 / 02 / 2019$ & Forte & Sem chuva \\
\hline $12 / 02 / 2019$ & Forte & Moderada \\
\hline $13 / 02 / 2019$ & Muito Forte & Moderada \\
\hline $14 / 02 / 2019$ & Muito Forte & Sem chuva \\
\hline
\end{tabular}

Fonte: Elaborado pelo autor (2019).

Após a tabulação dos dados, eles foram plotados em um gráfico comparativo mostrando as percepções dos voluntários e a previsão de chuvas pelas agências oficiais. Podemos destacar a diferença entre a percepção dos voluntários (população) e a chuva 
prevista, mostrando que a ferramenta contribuiu para trazer essa contradição à análise de agentes desencadeadores de novas sensações. Essa diferença pode ser vista na figura 12. Figura 12 - Comparativo entre a percepção da população e as previsões meteorológicas.

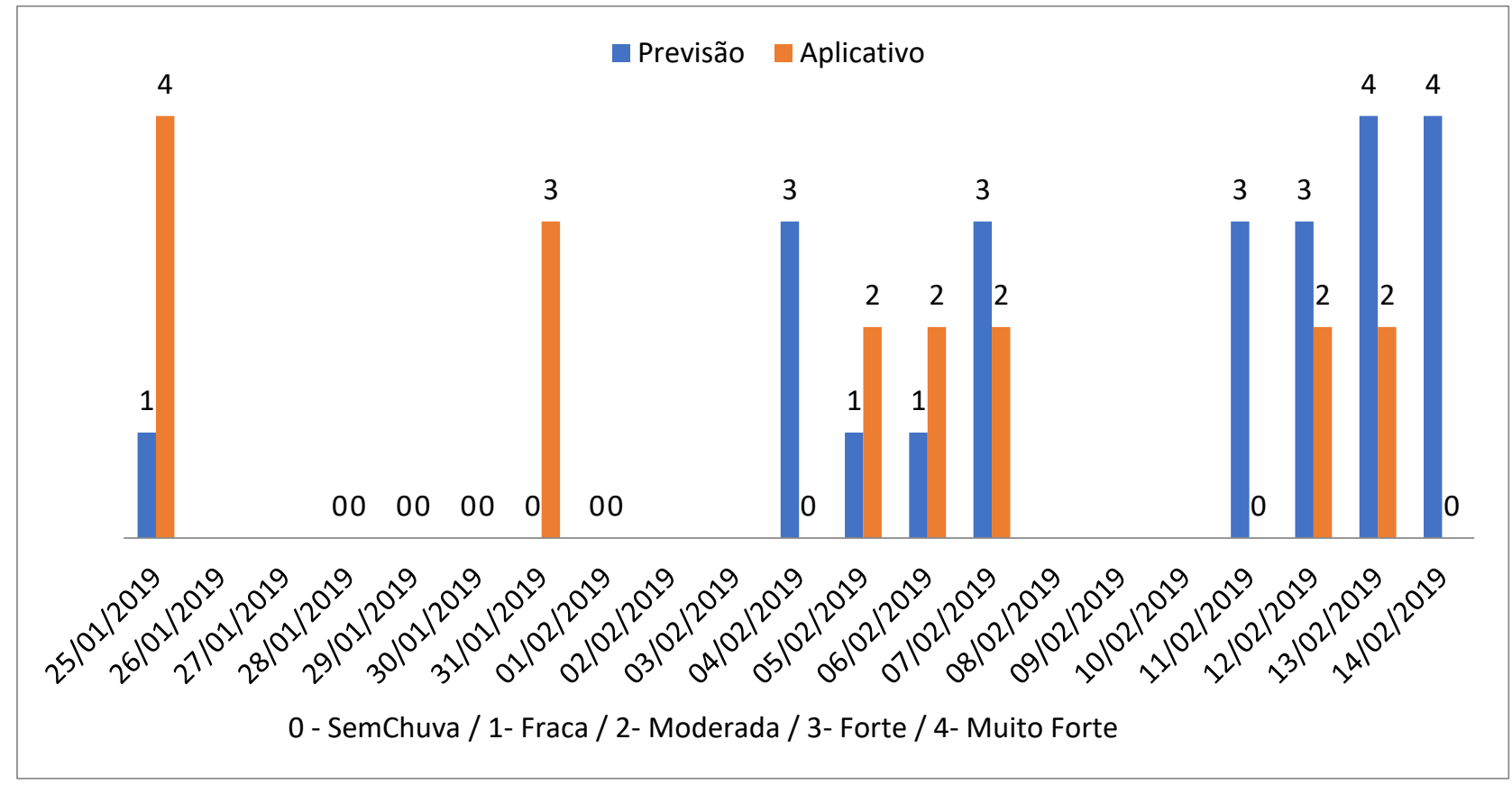

Fonte: Elaborado pelo autor (2019).

\section{CONSIDERAÇOES FINAIS}

Ao realizar o experimento durante os testes, podemos ver o grande desafio de envolver as pessoas e propor um aumento no entendimento do que significa compartilhar o sensemaking e o conceito de JCS, dentro do contexto crítico de emergência na prevenção de chuvas na cidade de Nova Friburgo, ou seja, a solução proposta é uma construção tecno-social, com treinamentos e mudanças de paradigmas.

As Figuras 11 e 12 mostram um aumento de informações e detalhes para a tomada de decisão de agentes da defesa civil que não existiam anteriormente com instrumentos oficiais. Isso pode ser identificado pelas cores diferentes da intensidade das chuvas dos sensores humanos distribuídos pela cidade. E essas são mais variáveis que alimentam de informação a equipe de emergência e que podem auxiliar na tomada de decisão e ações de resposta.

A pesquisa apresenta uma estrutura para orientar o desenvolvimento de uma solução sociotécnica que possibilite a conscientização da situação da chuva além de simples troca de mensagens, e informações, bem como a visualização de contribuições em um mapa. O mapa e as mensagens são vias criadas pela ferramenta para compartilhar as percepções da chuva entre a população e os agentes. Com a definição da solução, ela foi posta em prática durante um teste com voluntários da defesa civil, e os resultados obtidos por meio de entrevistas e questionários mostram que as informações colaborativas e compartilhadas são de grande valia para melhorar a consciência da situação dos agentes. $O$ relato de todas as pessoas envolvidas indicou que o uso de seres humanos como sensores de chuva pode ser a janela que faltava para que os agentes tenham uma visão geral da situação local das chuvas e um panorama da percepção da população sobre o impacto das chuvas. 


\section{REFERÊNCIAS}

AGENDA 21 NOVA FRIBURGO. Plano de Ação das Bacias Hidrográficas: documento Base da Agenda 21 local Nova Friburgo. Planos de ação para o Desenvolvimento Sustentável. ISER. Nova Friburgo, RJ. 2011.

AKEN, J. E. V. Management Research Based on the Paradigm of the Design Sciences: The Quest for Field-Tested and Grounded Technological Rules. Journal of Management Studies, v. 41, n. 2, p. 219-246, 2004.

ATTFIELD, S.; BLANDFORD, A. Making sense of digital footprints in team-based legal investigations: the acquisition of focus. Human-Computer Interaction, v. 26, n. 1-2,p. 3871, 2011.

\section{ÁVILA, A.G.N., Un Marco de Calidad Total para la Evaluación y Mejora de la Gestión} de Planes de Emergencia. Tesis Doctoral - Valencia, España, 2018.

CARVALHO, P. V. R.; HUBER G. ; RIGHI, A. W. ; LEMOS, C. ; EMYGDIO, K.; GOMES, J. O.; Firefighting emergency response exercise ? an analysis of standardization and resilience. In: INTERNATIONAL CONFERENCE ON INFORMATION SYSTEMS FOR CRISIS RESPONSE AND MANAGEMENT, 13., 2016, Rio de Janeiro. ISCRAM 2016 Conference Proceedings. Bruxelas: ISCRAM, 2016.

CBMERJ. Corpo de bombeiros do Estado do Rio de janeiro. CBMERJ museu histórico. Disponível em http://www.museu.cbmerj.rj.gov.br/. Acessado em 10 ago. 2017.

CEMADEN. In: Seminário Nacional de Avaliação dos Alertas do Centro Nacional de Monitoramento e Alertas de Desastres Naturais, 1.. 2017. Anais... São Jose dos Campos: 2017. Disponível em: http://www.cemaden.gov.br/i-seminario-de-avaliacao-dealertas-do-cemaden/ Acesso em: 10 jan. 2018.

CEMADEN. Centro nacional de monitoramento e alertas de desastres naturais. Disponível em: <http://www.cemaden.gov.br >. Acesso em: 10 jan. 2018.

CEPED/UFSC. Centro Universitário De Estudos e Pesquisas Sobre Desastres/ Universidade Federal de Santa Catarina. Capacitação básica em Defesa Civil. Florianópolis: CAD UFSC, 2012.

CHANG, Z.; LI, S. Collaboration enabled GIS Tools for Emergency Operation Centre. In: LI, J.; ZLATANOVA, S.; FABBRI, A. (eds): Geomatics Solutions for Disaster Management. Lecture Notes in Geoinformation and Cartography, Berlin Heidelberg, Germany: Springer, pp. 305-320, 2007.

SECRETARIA NACINAL DE DEFESA CIVIL. Ministério da Integração ntegração Nacional, Secretaria Nacional de Defesa Civil, Portaria no 314, de 17 de outubro de 2012

SECRETARIA NACINAL DE DEFESA CIVIL. Glossário de Defesa Civil. Disponível em: http://www.defesacivil.gov.br/glossario/index1.asp. Acesso em: 10 jan. 2018.

DOLIF, E.; ENGELBRECHT, A.; JATOBÁ, A.; SILVA, A., GOMES, J.; BORGES, M.; NOBRE, C.; CARVALHO, P.; Resiliência e fragilidade no sistema ALERTA RIO: um 
estudo de campo sobre a tomada de decisão de analistas. Brasil: Rio de Janeiro, RJ, 2013.

FAISAL, S.; ATTFIELD, S.; BLANDFORD, A. A classification of sensemaking representations. CHI '09 EXTENDED ABSTRACTS ON HUMAN FACTORS IN COMPUTING SYSTEMS. Proceedings..., New York, NY: ACM, 2009.

GAMPELL, A. V.; GAILLARD, J. C. Stop Disasters 2.0: Video Games as Tools for Disaster Risk Reduction. International Journal of Mass Emergencies \& Disasters, v. 34, n. 2, 2016.

GASPARINI, M. F.; Trabalho rural, saúde e contextos socioambientais- estudo de caso sobre a percepção dos riscos associados à produção de flores em comunidades rurais do município de Nova Friburgo, Rj. (dissertação de mestrado), Escola Nacional de Saúde Pública Sergio Arouca (ENSP/FIOCRUZ). Rio de Janeiro. 2012. 69 p.

GRANT, T. GIS A Meta-theory of Command \& Control in Emergency Management. In: INTERNATIONAL CONFERENCE ON INFORMATION SYSTEMS FOR CRISIS RESPONSE AND MANAGEMENT (ISCRAM), Proceedings..., 2017.

GOODCHILD, M. Citizens as sensors: the world of volunteered geography. GeoJournal, v. 69, n. 4, p. 211-221, 2007.

HEVNER, A. R.; MARCH S. T.; PARK J.; RAM S. Design Science in Information Systems Research. MIS Quarterly, v. 28, n. 1, p. 75-105, 2004.

HOLLNAGEL, E.; WOODS, D. D. Joint cognitive systems: Foundations of cognitive systems engineering. Boca Raton, FL, United States: Taylor \& Francis/CRC, 2005.

JENSEN, E. Sensemaking in military planning: a methodological study of command teams, Cognition. Technology and Work, v. 11, n. 2, p. 103-118, 2009.

JOHANNESEN, L. Maintaining common ground: An analysis of cooperative communication in the operating room. Improving Healthcare Team Communication: Building on Lessons from Aviation and Aerospace. P. 179-203. 2008.

KIRSH, D. Thinking with external representations, Al \& Soc, v. 25, p. 441-454. 2010. DOI: https://doi.org/10.1007/s00146-010-0272-8

KLEIN, G.; ROSS, K. G.; MOON, B. M.; KLEIN, D. E.; HOFFMAN, R. R.; HOLLNAGEL, E. Macrocognition. IEEE Intelligent Systems, v. 18, n. 3, 81-85, 2003.

KLEIN, G. The strengths and limitations of teams for detecting problems. Cognition, Technology and Work, v. 8, n. 4, pp. 227-236, 2006.

KLEIN, G.; MOON, B.; HOFFMAN, R. R. Making sense of sensemaking I: Alternative perspectives. IEEE Intelligent Systems, v. 21, p. 4, pp. 70-73, 2006b.

KLEIN, G.; PHILLIPS, J. K.; RALL, E. L.; PELUSO, D. A; A data-frame theory of sensemaking. In: INTERNATIONAL CONFERENCE ON NATURALISTIC DECISION MAKING, 6. 2007. Proceedings..., Mahwah, NJ: Erlbaum, 2007. 
LANDGREN, J.; Fire crew enroute sensemaking in emergency response. In:

INTERNATIONAL CONFERENCE ON INFORMATION SYSTEMS FOR CRISIS RESPONSE AND MANAGEMENT (ISCRAM2004), 1., 3rd-4th May. Proceedings..., Brussels, Belgium, 2004.

LANDGREN, J.; Shared use of information technology in emergency response work: results from a field experiment. In: CONFERENCE ON INFORMATION SYSTEMS FOR CRISIS RESPONSE AND MANAGEMENT (ISCRAM2005), 2., 18th-20th April, Proceedings..., Brussels, Belgium, 2005a.

LANDGREN, J.; Supporting fire crew sensemaking enroute to incidents. International Journal of Emergency Management, v. 2, n. 3, pp. 176-188, $2005 \mathrm{~b}$.

LEY, B.; LUDWIG, T.; PIPEK, V.; RANDALL, D.; REUTER, C.; WIEDENHOEFER, T.; Information and Expertise Sharing in Inter-Organizational Crisis Management, Computer Supported Cooperative Work (CSCW), v. 23, p. 347-387, 2014.

LIMA A. A.; GOMES O. S.; AGUIAR I. S. Voluntariado em Defesa Civil: Inovação, Educação e Formação para Redução de Riscos e Desastres, RECITE, v. 4, n. 2, 2019.

LIU, S. B.; PALEN, L. The New Cartographers: Crisis Map Mashups and the Emergence of Neogeographic Practice. Cartography and Geographic Information Science, v. 37, n. 1, pp 69-90. 2010.

NETO, M. C. Legal aspects of Civil Defense activities. Ministry of National Integration. National Secretariat of Civil Defense. 2007.

PIROLLI, P.; CARD, S. The sense-making process and leverage points for analyst technology as identified through cognitive task analysis. In: INTERNATIONAL CONFERENCE ON INTELLIGENCE ANALYSIS, 2-4, Proceedings..., 2005.

PIROLLI, P.; RUSSELL, D. M. Introduction to this Special Issue in Sensemaking. HumanComputer Interaction, v. 26, n.1-2, pp. 1-8, 2011.

POBLET, Marta; GARCÍA-CUESTA, Esteban; CASANOVAS, Pompeu. Crowdsourcing Tools for Disaster Management: A Review of Platforms and Methods. Lecture Notes in Computer Science. v. 8929, p. 261-274. 2014. DOI: 10.1007/978-3-662-45960-7_19.

REUTER, C.; LUDWIG, T.; KAUFHOLD, M. A.; PIPEK, V. XHELP: Design of a CrossPlatform Social-Media Application to Support Volunteer Moderators in Disasters. In: ANNUAL ACM CONFERENCE ON HUMAN FACTORS IN COMPUTING SYSTEMS (CHI '15), 33., April 2015, Proceedings..., p.4093-4102. DOI: https://doi.org/10.1145/2702123.2702171

ROMANO, M.; ONORATI, T.; AEDO, I.; Diaz, P. Designing mobile applications for emergency response: Citizens acting as human sensors. Sensors, v. 16, n. 3, p. 1-17, 2016. DOI: http://doi.org/10.3390/s16030406

SHIH, P. C.; HAN, K.; CARROLL, J. M. Using social multimedia content to inform emergency planning of recurring and cyclical events in local communities. Journal of Homeland Security and Emergency Management, v. 12, n. 3, p. 627-652, 2015. DOI: http://doi.org/10.1515/jhsem-2014-0071 
SODEN, R.; BUDHATHOKI, N.; PALEN, L. Resilience-building and the crisis informatics agenda: Lessons learned from Open Cities Kathmandu. In: INTERNATIONAL CONFERENCE ON INFORMATION SYSTEMS FOR CRISIS RESPONSE AND MANAGEMENT (ISCRAM 2014),11., Proceedings..., Pennsylvania, 2014.

TAN, M.; PRASANNA, R.; STOCK, K.; HUDSON, D. E.; LEONARD, G.; JOHNSTON, D. Mobile applications in crisis informatics literature: A systematic review. International Journal of Disaster Risk Reduction, v. 24, 2017.

WEICK, K. E. Sensemaking in Organizations. California, USA: SAGE, 1995.

WEICK, K. E; SUTCLIFFE, K. M; OBSTFELD, D. Organizing and the process of sensemaking, Organization Science, v. 16, n. 4, pp. 409-421., 2005. 